Check for updates

Cite this: RSC Adv., 2018, 8, 2485

Received 14th October 2017 Accepted 23rd December 2017

DOI: 10.1039/c7ra11347a

rsc.li/rsc-advances

\section{Glucose monitoring in living cells with single fluorescent protein-based sensors $\uparrow$}

\author{
Hanyang Hu, ${ }^{\text {ac }}$ Yufeng Wei, ${ }^{\text {ac }}$ Daocheng Wang, ${ }^{\text {ac }} \mathrm{Ni} \mathrm{Su},{ }^{\text {ac }}$ Xianjun Chen, ${ }^{\text {ac }}$ \\ Yuzheng Zhao, ac Guixia Liu (D) *c and Yi Yang (D) *ab
}

Glucose is the main source of energy and carbon in organisms and plays a central role in metabolism and cellular homeostasis. However, the sensitive fluctuation of glucose in living cells is difficult to monitor. Thus, we developed a series of ratiometric, highly responsive, single fluorescent protein-based glucose sensors of wide dynamic range by combining a circularly permuted yellow fluorescent protein with a bacterial periplasmic glucose/galactose-binding protein. We used these sensors to monitor glucose transport in living Escherichia coli cells, and found that the cells take up glucose within 10 min to maintain physiological glucose levels, and observed the differences in glucose uptake and glucose metabolism between wild-type and Mlc knockout cells. These sensors can be specific and simple tools for glucose detection in vitro and non-invasive tools for real-time monitoring of glucose metabolism in vivo.

\section{Introduction}

Glucose is the main source of energy and carbon in most organisms, from bacteria to humans. Changes in glucose uptake, release, and metabolism are associated with regulation of various physiological and pathological phenomena, such as cell growth, cell proliferation, cell differentiation, cell death, insulin secretion, obesity, and diabetes. ${ }^{\mathbf{1 - 3}}$ Therefore, sensitive and selective measurement of glucose has become significant. Radiolabeling, chromatography, and mass spectrometry have been used effectively to quantify glucose. ${ }^{4}$ However, these methods have limited spatiotemporal resolution and are unsuitable for real-time imaging of glucose metabolism in living cells.

To monitor glucose in situ, fluorescence resonance energy transfer (FRET)-based glucose biosensors with different affinity have been developed and proven to be useful for imaging glucose flux in living cells. ${ }^{5-10}$ These sensors are based on enhanced cyan fluorescent protein/enhanced yellow fluorescent protein FRET pair and glucose/galactose-binding protein (GGBP) of Escherichia coli. GGBP is a bacterial periplasmic-

${ }^{a}$ Synthetic Biology and Biotechnology Laboratory, State Key Laboratory of Bioreactor Engineering, Shanghai Collaborative Innovation Center for Biomanufacturing Technology, East China University of Science and Technology, 130 Mei Long Road, Shanghai 200237, China

${ }^{b}$ Optogenetics \& Synthetic Biology Interdisciplinary Research Center, CAS Center for Excellence in Brain Science, Shanghai Institutes for Biological Sciences, Chinese Academy of Sciences, Shanghai 200031, China. E-mail: yiyang@ecust.edu.cn

'Shanghai Key Laboratory of New Drug Design, School of Pharmacy, East China University of Science and Technology, 130 Mei Long Road, Shanghai 200237, China. E-mail: gxliu@ecust.edu.cn

$\dagger$ Electronic supplementary information (ESI) available. See DOI: $10.1039 / \mathrm{c} 7 \mathrm{ra} 11347 \mathrm{a}$ binding protein that exhibits a hinge-twist conformational change upon glucose binding. ${ }^{11-13}$ Unfortunately, the fluorescence changes of these FRET sensors are small, which fall into $10-70 \%,{ }^{5-10}$ and this limits their applications in highthroughput screen and monitoring subtle metabolic changes.

Recently, we have reported a series of metabolite sensors, including NADH (Frex), ${ }^{14} \mathrm{NAD}+/ \mathrm{NADH}$ ratio (SoNar), ${ }^{15,16} \mathrm{NADPH}$ (iNap) ${ }^{17}$ and histidine (FHisJ) ${ }^{18}$ based on circularly permuted yellow fluorescent protein (cPYFP). In cpYFP, the original $\mathrm{N}$ - and C-termini are fused by a polypeptide linker, and new termini are introduced close to the fluorophore, making its fluorescence highly sensitive to the protein's conformation. ${ }^{\mathbf{1 4 - 1 8}}$ Compared with FRET-based sensors, cpYFP-based sensors often have larger fluorescence changes; in specific, Frex, ${ }^{14}$ SoNar, ${ }^{15,16}$ iNap $^{17}$ and FHisJ $^{\mathbf{1 8}}$ sensors have more than 500\% dynamic range, rendering them capable of tracking subtle metabolic changes.

To maximize the existing technical advantages, we inserted cpYFP into three linker locations of GGBP and developed a series of ratiometric, highly responsive, single fluorescent protein-based glucose sensors, denoted as FGBP (fluorescent GGBP). Among them, FGBP $_{1} \mathrm{~mm}$ sensor with a binding constant $\left(K_{\mathrm{d}}\right)$ of $1.0 \mathrm{mM}$ exhibited sevenfold fluorescence ratio changes and fit physiological applications.

\section{Experimental}

\subsection{Plasmid construction and strains}

To generate single fluorescent protein-based glucose indicators, the MglB DNA sequence coding for the mature GGBP (positions 70-927 relative to ATG) was amplified from E. coli genomic DNA by PCR with the primers P1 and P2 (sequences available in Table S1 $\dagger$ ) and cloned into BamHI-HindIII sites in the pRSETb 
vector (Invitrogen). The GGBP-cpYFP insertion variants were constructed by overlap PCR $^{19}$ using wild-type GGBP sequence and cpYFP from Frex. ${ }^{14}$ First, the coding sequences of $\mathrm{N}$ and $\mathrm{C}$ terminal domain of GGBP, and cpYFP were amplified using the primers $\mathrm{P} 1$ and $\mathrm{PR}, \mathrm{PF}$ and $\mathrm{P} 2$, and $\mathrm{P} 3$ and $\mathrm{P} 4$, respectively (sequences available in Table $\mathrm{S} 1 \dagger$ ). Second, the chimeric construct consisting of GGBP and cPYFP was produced using an overlapping PCR with the primers $\mathrm{P} 1$ and $\mathrm{P} 2$. This product was cloned into the BamHI/HindIII sites of pRSETb (Invitrogen), yielding pRSETb-FGBP (GGBP and cPYFP chimeras) (Fig. S1A and $\mathrm{S} 1 \mathrm{~B} \dagger$ ). We truncated the $\mathrm{N}$ and $\mathrm{C}$ terminal amino acid residue of cPYFP to expand the dynamic range of FGBP by PCR (Fig. S1C $\dagger$ ). To improve the affinity of the sensors, sited directed mutagenesis of $\mathrm{FGBP}_{27} \mu \mathrm{M}$ was generated by PCR (Fig. S1D $\dagger$ ). The electrophoresis data showed the protein size of different sensors (Fig. S1E†).

Mlc knockout strain is a derivative of $E$. coli JM109 (DE3). Mlc was deleted according to the method of Datsenko and Wanner ${ }^{20}$ using plasmid pKD4 or pKD3, leaving the start codon and seven codons at the $3^{\prime}$ end of the target gene. The resistance cassettes were eliminated as described previously. ${ }^{20}$ To overexpress Mlc, the Mlc gene was amplified from $E$. coli genomic DNA by PCR and cloned into BamHI-HindIII sites in the pCDFDuet1 vector (Novagen).

\subsection{Library construction}

Preliminary truncations of the $\mathrm{N}$ - and C-terminals of cpYFP indicated that deletions beyond five AAs of the $\mathrm{N}$ - and $\mathrm{C}$ terminals (data not shown) caused misfoldings. Therefore, the library was limited to the deletions of four AAs of the N- and Cterminals. Truncation combinations were amplified with Primers STAR HS DNA polymerase (Takara) and fused by T4 DNA ligase (Fermentas). Mutants with different affinities were engineered in $\mathrm{FGBP}_{27} \mu \mathrm{M}$, using overlap PCR, ${ }^{19}$ and then transferred to the pRSETb vector. The DNA sequence and amino acid sequence of $\mathrm{FGBP}_{1} \mathrm{mM}$ are in the "ESI note $\dagger$ " section.

\subsection{Protein expression and in vitro characterization}

All recombinant proteins with a $\mathrm{His}_{6}$-tag were expressed in $E$. coli JM109 (DE3) by the pRSETb expression plasmid as previously described. ${ }^{18}$ Proteins were purified with Ni-NTA His SpinTrap column.

Spectral measurement was performed in $20 \mathrm{mM}$ MOPS buffer (pH 7.4) by using a spectrofluorometer (EnSpire). Excitation spectra were recorded between 350 and $510 \mathrm{~nm}$, and emission at $528 \mathrm{~nm}$ as previously described. ${ }^{\mathbf{1 4 , 1 5}}$

For glucose titration, the protein was diluted in $20 \mathrm{mM}$ MOPS buffer ( $\mathrm{pH}$ 7.4) to a final concentration of $1 \mu \mathrm{M}$. The fluorescence value of protein was measured by a filter-based Synergy 2 Multi-Mode microplate reader using 400 BP $10 \mathrm{~nm}$, 485 BP $20 \mathrm{~nm}$ excitation, and 528 BP $20 \mathrm{~nm}$ emission (BioTek). The ratio $(R)$ was defined as the fluorescence intensity at $485 \mathrm{~nm}$ divided by the intensity at $400 \mathrm{~nm}$.

The $K_{\mathrm{d}}$ of each glucose sensor was determined by fitting to a single-site binding isotherm:

$$
S=\frac{R-R_{\text {apo }}}{R_{\text {sat }}-R_{\text {apo }}}=\frac{[\mathrm{L}]}{K_{\mathrm{d}}+[\mathrm{L}]}
$$

where $S$ is the fraction of sensor saturation, $[\mathrm{L}]$ is the concentration of glucose, $R$ is the fluorescence ratio $_{485 / 400}$ of sample, $R_{\text {apo }}$ is the ratio in the absence of ligand, and $R_{\text {sat }}$ is the ratio at saturation with ligand.

\subsection{Monitoring glucose transport in $E$. coli cells}

To monitor glucose transport in living cells, E. coli JM109 (DE3) cells carrying pRSETb-FGBP 1 mM were grown in Luria-Bertani medium containing $100 \mu \mathrm{g} \mathrm{ml}^{-1}$ ampicillin at $37{ }^{\circ} \mathrm{C}$ until the cultures reached about 0.6-0.8 OD. The expression of proteins was induced by $0.1 \mathrm{mM}$ IPTG at $18{ }^{\circ} \mathrm{C}$ overnight. E. coli cells were harvested by centrifugation at $4000 \times g$ for $30 \mathrm{~min}$ at $4{ }^{\circ} \mathrm{C}$, washed twice with M9 mini medium ( $\mathrm{pH} 7.4$, containing $100 \mathrm{mM}$ HEPES), and then incubated in the same buffer for $6 \mathrm{~h}$ to ensure low endogenous glucose levels.

After 6 h starving, E. coli cells were harvested by centrifugation, washed twice with M9 mini medium ( $\mathrm{pH} 7.4$, containing $100 \mathrm{mM}$ HEPES), and then suspended in the same buffer. Subsequently, $45 \mu$ l cultures (0.5 OD) were transferred into 384 well plates. Fluorescence emission at $528 \mathrm{~nm}$ (excitation at 400 and $485 \mathrm{~nm}$ ) was recorded for $5 \mathrm{~min}$ by Synergy 2 Multi-Mode microplate reader. M9 mini medium (5 $\mu$ l) with different glucose concentrations was added manually to the cultures. Fluorescence was then measured for $30 \mathrm{~min}$. Fluorescence values were background corrected by subtracting the intensity of E. coli JM109 (DE3) cell samples not expressing sensors.

\section{Results and discussion}

\subsection{Generation of cpYFP-based sensors for glucose}

To engineer a cpYFP-based indicator for glucose, bacterial periplasmic $\mathrm{GGBP}^{\mathbf{1 1 - 1 3}}$ was chosen as a suitable glucose-binding detector because of the following findings: (1) glucose binds to GGBP with high specificity ${ }^{11,12}$ and (2) glucose binding to GGBP results in a dramatic conformational change demonstrated by $\mathrm{X}$-ray and NMR analyses, ${ }^{13}$ as shown in Fig. 1A. In addition, GGBP was used as a sensor domain of FRET-based glucose indicators as previously reported..$^{\mathbf{8} 9}$

According to crystallographic structures of GGBP, ${ }^{\mathbf{1 3}, 18}$ chimeric proteins were generated by inserting cpYFP into the three flexible linker regions of GGBP, namely, Gly109-Glu114, Thr253-Asn256, and Val293-Val296 (Fig. 1A and B). Among them, the chimera with cpYFP inserted between Pro294 and Tyr295 of GGBP showed a 2.1-fold increase in the ratio of fluorescence when excited at 485 and $400 \mathrm{~nm}$ upon glucose addition (Fig. 1C, Table 1). Fluorescence titration studies showed that the Pro294/Tyr295 chimera named FGBP $3.1 \mu \mathrm{M}$ had an apparent dissociation constant $\left(K_{\mathrm{d}}\right) \sim 3.1 \mu \mathrm{M}$ for glucose at pH 7.4 (Fig. 1D, Table 1). Similar to other cpYFP-based sensors, ${ }^{17,18}$ FGBP $_{3.1} \mu \mathrm{M}$ has two typical excitation peaks around 420 and $500 \mathrm{~nm}$ and one emission peak near $515 \mathrm{~nm}$ (Fig. 1E). 

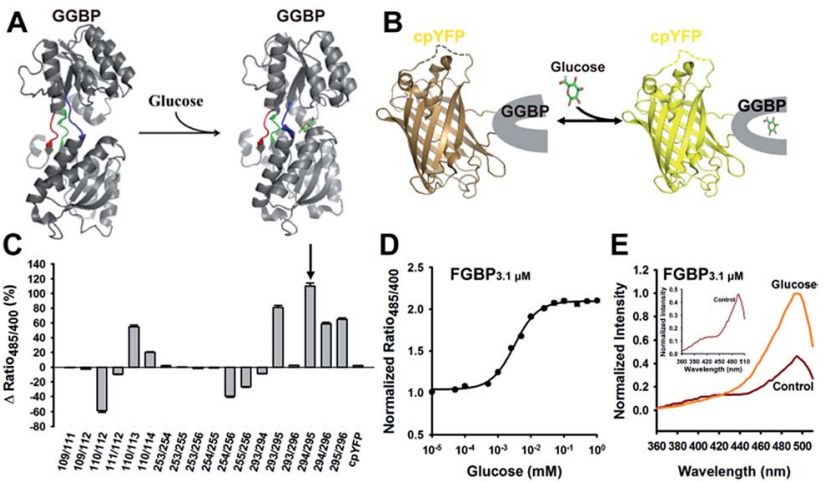

Fig. 1 Generation of cpYFP-based glucose sensors. (A) Crystallographic structures of glucose-free (PDB ID code 2FW0) and glucosebinding (PDB ID code 2FVY) GGBP from E. coli are drawn using the molecular-graphics software PyMOL based on Protein Data Bank files. The colored ribbon parts [residues 109-114 (blue), 253-256 (green), 293-296 (red)] represent the flexible and target region for the insertion of cpYFP to generate glucose indicators. (B) Design of glucose sensor, in which cpYFP was inserted into the flexible linker region of GGBP. Binding of glucose (green and red) changes protein conformation and fluorescence. (C) Comparison of cpYFP and 18 sensor variants in glucose responsiveness. (D) Titration of the chimeric Pro294/Tyr295

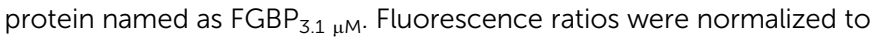
the control condition in the absence of glucose. (E) Excitation spectra of $\mathrm{FGBP}_{3.1 \mu \mathrm{M}}$ with or without $100 \mathrm{mM}$ glucose, normalized to the peak intensity in the glucose condition. Emission was measured at $528 \mathrm{~nm}$ For $C$ and $D$, data are presented in three biological replicates, and error bars represent SEM.

\subsection{Optimization improves the responsiveness and affinity of FGBP sensors}

To maximize the response magnitude of sensors, we created a cpYFP-terminal truncation library between GGBP and cpYFP of $\mathrm{FGBP}_{3.1 \mu \mathrm{M}}$ (Fig. 2A) and found that the $\mathrm{FGBP}_{3.1 \mu \mathrm{M}}$ variant $\mathrm{N} 3 \mathrm{C} 4$ manifests the most dramatic increase in the presence of glucose, as measured by the ratio of fluorescence excited at 485 and $420 \mathrm{~nm}$ (Fig. 2B). Fluorescence titration studies showed that the N3C4 variant (named $\mathrm{FGBP}_{27 \mu \mathrm{M}}$ ) had an apparent $K_{\mathrm{d}}$ of $\sim 27 \mu \mathrm{M}$ for glucose (Fig. 2C and Table 1).

Physiological glucose level has been estimated in the range of 0.4-24 mM, such as $2-5 \mathrm{mM}$ in plants, ${ }^{7} 1.5 \mathrm{mM}$ in yeast, ${ }^{21}{ }^{3-}$ $9 \mathrm{mM}$ in blood, ${ }^{22} 1-10 \mathrm{mM}$ in liver, ${ }^{23}$ and $0.4-24 \mathrm{mM}$ in the intestine, ${ }^{24}$ far exceeding the dissociation constants of $\mathrm{FGBP}_{27 \mu \mathrm{M}}$ for glucose. To tune the affinity of the $\mathrm{FGBP}_{27 \mu \mathrm{M}}$ sensor, we further created variants of the sensor with single site-
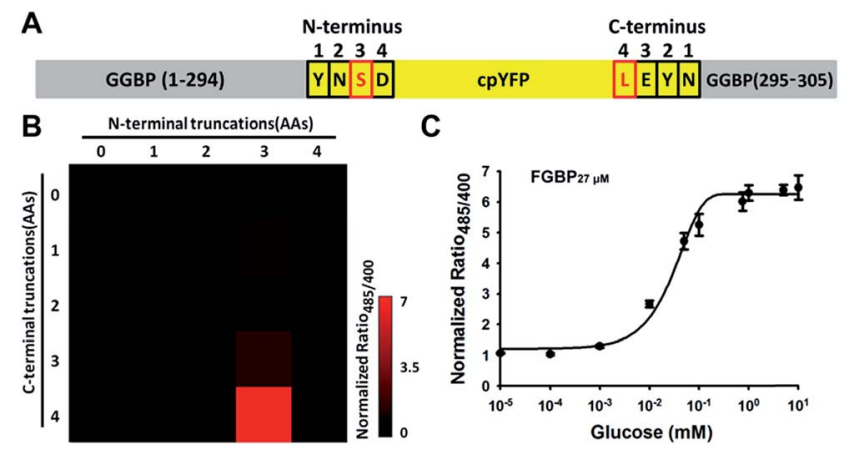

Fig. 2 Optimization improves the responsiveness of glucose sensor.

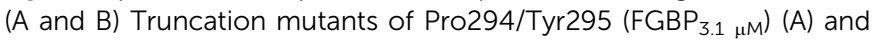
their fluorescence response (B) toward $100 \mathrm{mM}$ glucose. The most responsiveness mutant $\mathrm{N} 3 \mathrm{C} 4$ named $\mathrm{FGBP}_{27} \mu \mathrm{M}$ is indicated in red boxes. (C) Titration curve of $\mathrm{FGBP}_{27 \mu \mathrm{M}}$. Fluorescence ratios were normalized to the control condition in the absence of glucose. Data are presented in three biological replicates, and error bars represent SEM.

directed mutagenesis of three key amino acid residues around the glucose binding pocket (Fig. 3A) ${ }^{25-27}$ The three mutants, i.e., N256S, L238S, and A213R, had different affinities, with apparent $K_{\mathrm{d}}$ values of $\sim 380 \mu \mathrm{M}, \sim 1.0 \mathrm{mM}$, and $\sim 3.2 \mathrm{mM}$, and were denoted as $\mathrm{FGBP}_{380 \mu \mathrm{M}}, \mathrm{FGBP}_{1} \mathrm{mM}$, and $\mathrm{FGBP}_{3.2} \mathrm{~mm}$, respectively (Fig. 3B and Table 1). Considering the maximum fluorescence ratio change, affinity, and expression level, we chose $\mathrm{FGBP}_{1 \mathrm{mM}}$, which covers the physiological blood glucose range, for further characterization (Table 1).

Similar to $\mathrm{FGBP}_{3.1 \mu \mathrm{M}}, \mathrm{FGBP}_{1 \mathrm{mM}}$ also has two typical excitation peaks around 420 and $500 \mathrm{~nm}$ and one emission peak near $515 \mathrm{~nm}$ (Fig. 3C). Upon glucose binding, the fluorescence of $\mathrm{FGBP}_{1 \mathrm{~mm}}$ excited at $485 \mathrm{~nm}$ showed a 6.5 -fold increase, and the fluorescence excited at $400 \mathrm{~nm}$ was almost constant (Fig. 3D). Apart from glucose and galactose, none of the other sugars tested induced a significant change in ratio at 1 and $100 \mathrm{mM}$ concentrations (Fig. 3E), showing the high selectivity of FGBP $_{1 \mathrm{mM}}$ toward glucose. Glucose is expected to be present in significantly higher concentrations than galactose; thus, $\mathrm{FGBP}_{1 \mathrm{mM}}$ is suitable for glucose monitoring in living cells.

Similar to all other genetically encoded sensors based on cpYFP, FGBP $_{1} \mathrm{~mm}$ depended on $\mathrm{pH}$ when excited at $485 \mathrm{~nm}$; however, FGBP $1 \mathrm{~mm}$ fluorescence excited at $400 \mathrm{~nm}$ is much more $\mathrm{pH}$ resistant (Fig. 4A). At modest $\mathrm{pH}$ fluctuations, the $\mathrm{pH}$ effects of $\mathrm{FGBP}_{1} \mathrm{~mm}$ can be corrected by measuring the

Table 1 Properties of five glucose sensors ${ }^{a, b}$

\begin{tabular}{lllll}
\hline Sensor & Engineering & $R_{\text {sat }} / R_{\text {apo }}(\%)$ & $K_{\mathrm{d}}(\mathrm{mM})$ & Detection range $(\mathrm{mM})$ \\
\hline $\mathrm{FGBP}_{3.1 \mu \mathrm{M}}$ & $\mathrm{P} 294 / \mathrm{Y} 295$ & 210 & 0.0031 & $0.0005-0.02$ \\
$\mathrm{FGBP}_{27 \mu \mathrm{M}}$ & $\mathrm{P} 294 / \mathrm{Y} 295, \mathrm{~N} 3 \mathrm{C} 4$ & 590 & 0.027 & $0.0009-0.86$ \\
$\mathrm{FGBP}_{380 \mu \mathrm{M}}$ & $\mathrm{P} 294 / \mathrm{Y} 295, \mathrm{~N} 3 \mathrm{C} 4, \mathrm{~N} 256 \mathrm{~S}$ & 510 & 0.38 & $0.014-10$ \\
$\mathrm{FGBP}_{1 \mathrm{mM}}$ & $\mathrm{P} 294 / \mathrm{Y} 295, \mathrm{~N} 3 \mathrm{C} 4, \mathrm{~L} 238 \mathrm{~S}$ & 690 & 1.0 & $0.026-38$ \\
$\mathrm{FGBP}_{3.2 \mathrm{mM}}$ & $\mathrm{P} 294 / \mathrm{Y} 295, \mathrm{~N} 3 \mathrm{C} 4, \mathrm{~A} 213 \mathrm{R}$ & 630 & 3.2 & $0.09-110$
\end{tabular}

${ }^{a}$ P294/Y295, cpYFP was inserted between Pro294 and Tyr295 amino acids of GGBP. ${ }^{b}$ N3C4, N-terminal 3 amino acids and C-terminal 4 amino acids of cpYFP were truncated. 
A
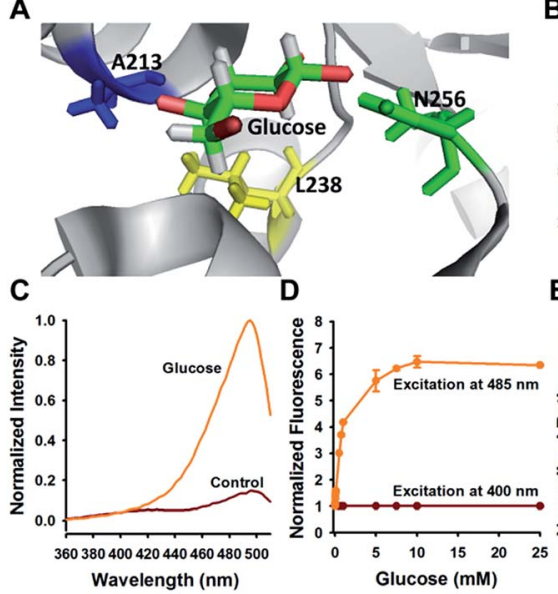

B

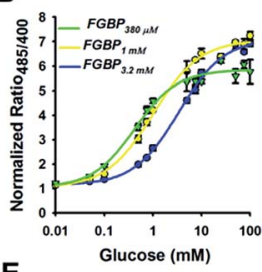

$E$

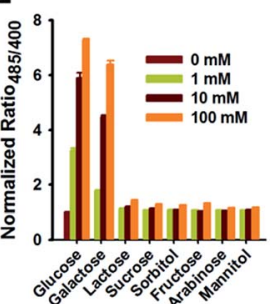

Fig. 3 Optimization tunes the affinity of glucose sensor. (A) Crystallographic structure of GGBP (PDB ID code 2FVY) showing the glucosebinding pocket. Three sites (A213, L238, and N256) are potential for sensor affinity improvement. (B) Titration curves of A213R (named $\mathrm{FGBP}_{3.2} \mathrm{~mm}$ ), L238S (named $\mathrm{FGBP}_{1} \mathrm{~mm}$ ), and N256S (named $\mathrm{FGBP}_{380} \mu \mathrm{M}$ ) mutants. (C) Excitation spectra of $\mathrm{FGBP}_{1} \mathrm{mM}$ with or without $100 \mathrm{mM}$ glucose, normalized to the peak intensity in the glucose condition. Emission was measured at $528 \mathrm{~nm}$. (D) Fluorescence intensities of $\mathrm{FGBP}_{1} \mathrm{mM}$ with excitation at 400 or $485 \mathrm{~nm}$ normalized to the initial value; emission at $528 \mathrm{~nm}$. (E) Substrate specificity of $\mathrm{FGBP}_{1} \mathrm{~mm}$ as measured by ratio ${ }_{485 / 400}$ in the presence of various sugar ligands. Data were normalized to the control condition in the absence of ligand. For B, D, and E, data are presented in three biological replicates, and error bars represent SEM.
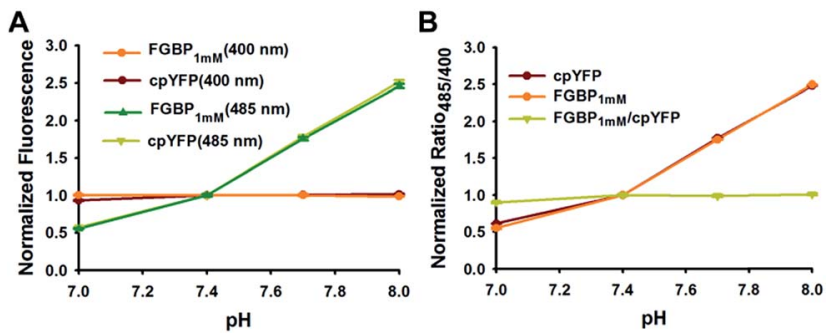

Fig. 4 Effect of $\mathrm{pH}$ on FGBP1 $\mathrm{mM}$ and cpYFP. (A) Fluorescence intensities of FGBP1 mM and cPYFP with excitation at $400 \mathrm{~nm}$ or $485 \mathrm{~nm}$, and emission at $528 \mathrm{~nm}$. (B) pH-dependency of the excitation ratio $485 / 400$ of $\mathrm{FGBP}_{1} \mathrm{mM}$ and $\mathrm{CPYFP}$. For $\mathrm{A}$ and $\mathrm{B}$, data are normalized to the fluorescence or ratio at $\mathrm{pH} 7.4$, and are presented in three biological replicates, and error bars represent SEM.

fluorescence of $\mathrm{FGBP}_{1} \mathrm{~mm}$ and cpYFP in parallel, due to their very similar $\mathrm{pH}$ responses (Fig. 4B).

\subsection{Real-time monitoring of intracellular glucose in living cells}

The ability of transport glucose across the plasma membrane is a common feature to nearly all cells, from the simple bacterium to the highly compartmented mammalian cells. ${ }^{28}$ To test the ability of $\mathrm{FGBP}_{1} \mathrm{~mm}$ to report changes in intracellular glucose levels, we expressed the $\mathrm{FGBP}_{1 \mathrm{mM}}$ sensor in living $E$. coli JM109 (DE3) cells. Fluorescence was uniform throughout the cell,

suggesting that this sensor was located in the cytoplasm but not cell surface (Fig. 5A). Addition of exogenous glucose into the culture medium induced a rapid, dose-dependent, and saturable increase in the fluorescence ratio (Fig. 5B-E), whereas addition of glucose analogs had no effect on fluorescence (Fig. 5C). This finding suggested that glucose was readily transported across the cell membrane of these bacteria. Michaelis-Menten fitting of $\mathrm{FGBP}_{1} \mathrm{~mm}$ 's fluorescence ratio versus extracellular glucose concentration produced a $K_{0.5}$ of $\sim 0.3 \mathrm{mM}$ (Fig. 5E), which is much higher than the $K_{\mathrm{m}}$ for ptsG in $E$. coli, the high-affinity glucose transporter in the plasma membrane. ${ }^{29}$ By contrast, only slight changes in the fluorescence ratio were observed in E. coli JM109 (DE3) cells expressing cpYFP instead of FGBP 1 mM when glucose was added to the cell culture medium (Fig. $5 \mathrm{~F}$ and $\mathrm{G}$ ), excluding the possibilities of fluorescence interference of $\mathrm{pH}$ variations of the cpYFP domain.

The phosphotransferase system (PTS) is the major sugar transport system in many Gram-positive and Gram-negative bacterial species; however, expression of ptsG is repressed by the Mlc (making large colonies) protein. ${ }^{30}$ To investigate the role of Mlc on glucose transport, we constructed Mlc knockout $E$. coli JM109 (DE3) cells. Compared with wild-type cells, we surprisingly found that glucose-induced the increase of fluorescence gradually returned to basal levels as the extracellular glucose was consumed in Mlc knockout cells (Fig. 5D and H), and Mlc

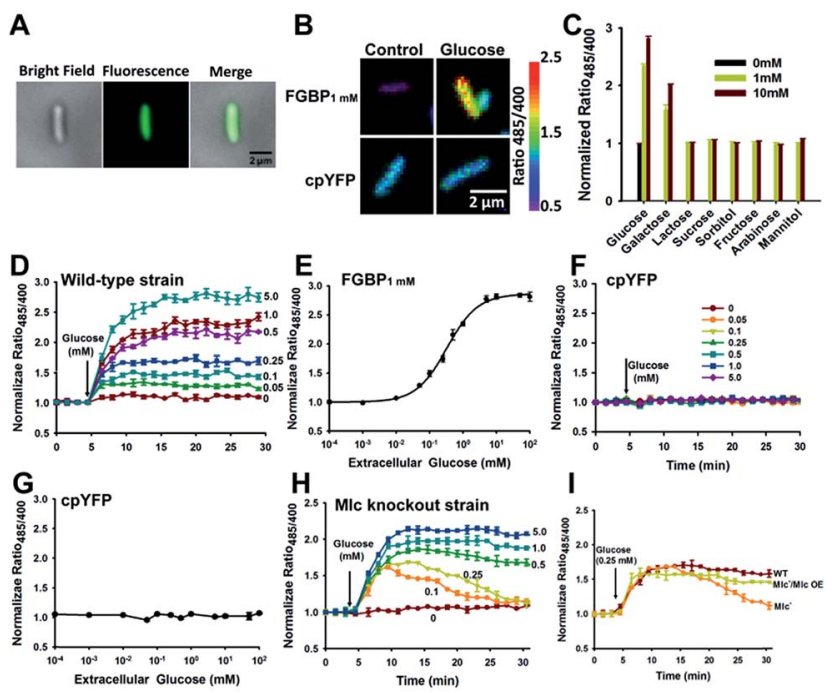

Fig. 5 Real-time monitoring of intracellular glucose in living cells. (A)

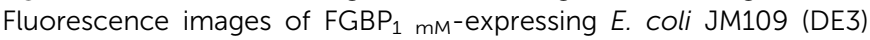
cells. (B) Fluorescence images of $\mathrm{FGBP}_{1} \mathrm{~mm}$ or $\mathrm{cpYFP}$-expressing cells before and after incubation with $25 \mathrm{mM}$ glucose. (C) Fluorescence responses of $\mathrm{FGBP}_{1} \mathrm{~mm}$ in live cells treated with exogenous glucose and its analogs. (D and F) Kinetics of $\mathrm{FGBP}_{1} \mathrm{~mm}(\mathrm{D})$ or cpYFP (F) fluorescence responses in E. coli JM109 (DE3) cells treated with exogenous glucose. (E and $G$ ) Fluorescence responses of $F_{G B P} \mathrm{~mm}(E)$ or cpYFP (G) in E. coli JM109 (DE3) cells after glucose addition for 20 min. $(\mathrm{H})$ Kinetics of $\mathrm{FGBP}_{1} \mathrm{~mm}$ fluorescence responses in Mlc knockout $E$. coli JM109 (DE3) cells treated with exogenous glucose. (I) Kinetics of $\mathrm{FGBP}_{1} \mathrm{~mm}$ fluorescence responses to glucose in wild-type or Mlc knockout E. coli JM109 (DE3) cells. For C-I, data are presented in three biological replicates, and error bars represent SEM. 
overexpression rendered the similarity in metabolic kinetics of these cells (Fig. 5I). These results imply that Mlc expression level not only regulates glucose uptake but also influences the rate of glucose metabolism.

\section{Conclusions}

In this work, we reported a series of ratiometric, highly specific, highly sensitive, and single fluorescent protein-based glucose sensors with different affinities. Among them, $\mathrm{FGBP}_{1} \mathrm{~mm}$ can detect glucose in the range of $0.02-40 \mathrm{mM}$, which covers the physiological glucose concentration in organisms. FGBP $_{1} \mathrm{~mm}$ displays a large dynamic range and is very useful for the realtime tracking of subtle changes in cell metabolism. FGBP $_{1 \mathrm{mM}}$ displays a $\sim 700 \%$ fluorescence change in vitro, almost 10 -fold greater than that of previously reported FRET-based glucose sensors, ${ }^{5-10}$ rendering it a highly responsive genetic-encoded sensor. Compared with FRET-based glucose sensors, FGBP sensors only have one fluorescent protein and are intrinsically ratiometric, allowing the built-in normalization of the fluorescence signals irrespective of variations in indicator protein concentrations. Considering the admirable properties of these sensors, we believe that FGBP sensors could be good alternatives to existing methods for intracellular glucose detection.

\section{Conflicts of interest}

The authors have declared no conflicts of interest.

\section{Acknowledgements}

This work was supported by National Key Research and Development Program of China (2017YFA050400 to Y. Y., 2017YFC0906900 to Y. Zhao), NSFC (31225008, and 31470833 to Y. Y., 31722033 , 91649123, and 31671484 to Y. Zhao), the Shanghai Science and Technology Commission (14XD1401400 and 16430723100 to Y. Y., and 15YF1402600 to Y. Zhao), Young Elite Scientists Sponsorship Program by Cast (to Y. Zhao), Shanghai Young Top-notch Talent (to Y. Zhao), the State Key Laboratory of Bioreactor Engineering (to Y. Y.), and the Fundamental Research Funds for the Central Universities (to Y. Y. and Y. Zhao).

\section{References}

1 R. J. DeBerardinis, J. J. Lum, G. Hatzivassiliou and C. B. Thompson, Cell Metab., 2008, 7, 11-20.

2 B. Ghesquiere, B. W. Wong, A. Kuchnio and P. Carmeliet, Nature, 2014, 511, 167-176.

3 A. R. Saltiel and C. R. Kahn, Nature, 2001, 414, 799-806.

4 K. Yamada, M. Saito, H. Matsuoka and N. Inagaki, Nat. Protoc., 2007, 2, 753-762.

5 B. H. Hou, H. Takanaga, G. Grossmann, L. Q. Chen, X. Q. Qu, A. M. Jones, S. Lalonde, O. Schweissgut, W. Wiechert and W. B. Frommer, Nat. Protoc., 2011, 6, 1818-1833.
6 C. Bermejo, F. Haerizadeh, H. Takanaga, D. Chermak and W. B. Frommer, Nat. Protoc., 2011, 6, 1806-1817.

7 K. Deuschle, B. Chaudhuri, S. Okumoto, I. Lager, S. Lalonde and W. B. Frommer, Plant Cell, 2006, 18, 2314-2325.

8 H. Takanaga, B. Chaudhuri and W. B. Frommer, Biochim. Biophys. Acta, 2008, 1778, 1091-1099.

9 M. Fehr, S. Lalonde, I. Lager, M. W. Wolff and W. B. Frommer, J. Biol. Chem., 2003, 278, 19127-19133.

10 K. Deuschle, S. Okumoto, M. Fehr, L. L. Looger, L. Kozhukh and W. B. Frommer, Protein Sci., 2005, 14, 2304-2314.

11 F. A. Quiocho and J. W. Pflugrath, J. Biol. Chem., 1980, 255, 6559-6561.

12 M. N. Vyas, N. K. Vyas and F. A. Quiocho, Biochemistry, 1994, 33, 4762-4768.

13 M. J. Borrok, L. L. Kiessling and K. T. Forest, Protein Sci., 2007, 16, 1032-1041.

14 Y. Zhao, J. Jin, Q. Hu, H. M. Zhou, J. Yi, Z. Yu, L. Xu, X. Wang, Y. Yang and J. Loscalzo, Cell Metab., 2011, 14, 555-566.

15 Y. Zhao, Q. Hu, F. Cheng, N. Su, A. Wang, Y. Zou, H. Hu, X. Chen, H. M. Zhou, X. Huang, K. Yang, Q. Zhu, X. Wang, J. Yi, L. Zhu, X. Qian, L. Chen, Y. Tang, J. Loscalzo and Y. Yang, Cell Metab., 2015, 21, 777-789.

16 Y. Zhao, A. Wang, Y. Zou, N. Su, J. Loscalzo and Y. Yang, Nat. Protoc., 2016, 11, 1345-1359.

17 R. Tao, Y. Zhao, H. Chu, A. Wang, J. Zhu, X. Chen, Y. Zou, M. Shi, R. Liu, N. Su, J. Du, H. M. Zhou, L. Zhu, X. Qian, H. Liu, J. Loscalzo and Y. Yang, Nat. Methods, 2017, 14, 720-728.

18 H. Hu, Y. Gu, L. Xu, Y. Zou, A. Wang, R. Tao, X. Chen, Y. Zhao and Y. Yang, Sci. Rep., 2017, 7, 43479.

19 R. M. Horton, Mol. Biotechnol., 1995, 3, 93-99.

20 K. A. Datsenko and B. L. Wanner, Proc. Natl. Acad. Sci. U. S. A., 2000, 97, 6640-6645.

21 B. Teusink, J. A. Diderich, H. V. Westerhoff, K. van Dam and M. C. Walsh, J. Bacteriol., 1998, 180, 556-562.

22 M. Konig, S. Bulik and H. G. Holzhutter, PLoS Comput. Biol., 2012, 8, e1002577.

23 K. R. Albe, M. H. Butler and B. E. Wright, J. Theor. Biol., 1990, 143, 163-195.

24 R. P. Ferraris, S. Yasharpour, K. C. Lloyd, R. Mirzayan and J. M. Diamond, Am. J. Physiol., 1990, 259, G822-G837.

25 T. J. Amiss, D. B. Sherman, C. M. Nycz, S. A. Andaluz and J. B. Pitner, Protein Sci., 2007, 16, 2350-2359.

26 O. V. Stepanenko, A. V. Fonin, O. V. Stepanenko, K. S. Morozova, V. V. Verkhusha, I. M. Kuznetsova, K. K. Turoverov, M. Staiano and S. D'Auria, J. Phys. Chem. $B$, 2011, 115, 9022-9032.

27 S. Joel, K. B. Turner and S. Daunert, ACS Chem. Biol., 2014, 9, 1595-1602.

28 M. Mueckler, Eur. J. Biochem., 1994, 219, 713-725.

29 S. Steinsiek and K. Bettenbrock, J. Bacteriol., 2012, 194, 5897-5908.

30 J. Plumbridge, Curr. Opin. Microbiol., 2002, 5, 187-193. 